\title{
Isolation and characterization of human articular chondrocytes from surgical waste after total knee arthroplasty (TKA)
}

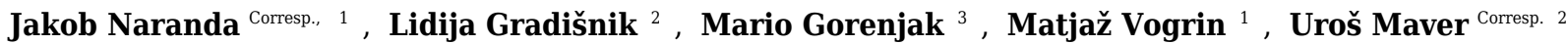 \\ 1 Department of Orthopaedics, University Medical Centre Maribor, Maribor, Slovenia \\ (t) Biomedical Sciences, University of Maribor, Faculty of Medicine, Maribor, Slovenia \\ 3 Center of Human Molecular Genetics and Pharmacogenomics, University of Maribor, Faculty of Medicine, Maribor, Slovenia \\ Corresponding Authors: Jakob Naranda, Uroš Maver \\ Email address: jakob.naranda@gmail.com,uros.maver@um.si
}

Background. Cartilage tissue engineering is a fast evolving field of biomedical engineering, in which the chondrocytes represent the most commonly used cell type. Since research in tissue engineering always consumes a lot of cells, simple and cheap isolation methods could form a powerful basis to boost such studies and enable their faster progress to the clinics. Isolated chondrocytes can be used for autologous chondrocyte implantation in cartilage repair, and are the base for valuable models to investigate cartilage phenotype preservation, as well as enable studies of molecular features, nature and scales of cellular responses to alterations in the cartilage tissue.

Methods. Isolation and consequent cultivation of primary human adult articular chondrocytes from the surgical waste obtained during total knee arthroplasty (TKA) was performed. To evaluate the chondrogenic potential of the isolated cells, gene expression of collagen type 2 (COL2), collagen 1 (COL1) and aggrecan (ACAN) was evaluated. Immunocytochemical staining of all mentioned proteins was performed to evaluate chondrocyte specific production.

Results. Cartilage specific gene expression of COL2 and ACAN have shown that the proposed protocol leads to isolation of cells with a high chondrogenic potential, possibly even specific phenotype preservation up to the second passage. COL1 expression has confirmed the tendency of the isolated cells dedifferentiation into a fibroblast-like phenotype already in the second passage, which confirms previous findings that higher passages should be used with care in cartilage tissue engineering. To evaluate the effectiveness of our approach, immunocytochemical staining of the evaluated chondrocyte specific products was performed as well.

Discussion. In this study, we developed a protocol for isolation and consequent cultivation of primary human adult articular chondrocytes with the desired phenotype from the surgical waste obtained during TKA. TKA is a common and very frequently performed orthopaedic surgery during which both femoral condyles are removed. The latter present the ideal source for a simple and relatively cheap isolation of chondrocytes as was confirmed in our study. 
1 Isolation and characterization of human articular chondrocytes from surgical waste after

2

3

4

5

6

7

8

9 10

26

27

28

29 total knee arthroplasty (TKA)

Short title: Alternative human chondrocyte isolation

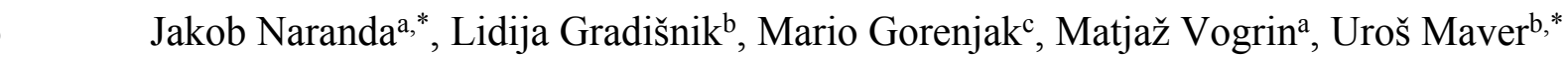

a University Medical Centre Maribor, Department of Orthopaedics, Ljubljanska ulica 5, SI-2000 Maribor, Slovenia

${ }^{b}$ University of Maribor, Faculty of Medicine, Institute of Biomedical Sciences, Taborska ulica 8, SI-2000 Maribor, Slovenia

${ }^{c}$ University of Maribor, Faculty of Medicine, Center of Human Molecular Genetics and Pharmacogenomics, Taborska ulica 8, SI-2000 Maribor, Slovenia

\section{*Corresponding authors:}

Jakob Naranda, MD

University Medical Centre Maribor, Department of Orthopedics

Ljubljanska ulica 5, SI-2000 Maribor, Slovenia

e-mail: jakob.naranda@gmail.com

prof. Uroš Maver, PhD, head of Institute of Biomedical Sciences

University of Maribor, Faculty of Medicine

Institute of Biomedical Sciences

Taborska ulica 8, SI-2000 Maribor, Slovenia

e-mail: uros.maver@um.si 


\section{ABSTRACT}

31 Background. Cartilage tissue engineering is a fast evolving field of biomedical engineering, in which the chondrocytes represent the most commonly used cell type. Since research in tissue engineering always consumes a lot of cells, simple and cheap isolation methods could form a powerful basis to boost such studies and enable their faster progress to the clinics. Isolated chondrocytes can be used for autologous chondrocyte implantation in cartilage repair, and are the base for valuable models to investigate cartilage phenotype preservation, as well as enable studies of molecular features, nature and scales of cellular responses to alterations in the cartilage tissue.

Methods. Isolation and consequent cultivation of primary human adult articular chondrocytes from the surgical waste obtained during total knee arthroplasty (TKA) was performed. To evaluate the chondrogenic potential of the isolated cells, gene expression of collagen type 2 (COL2), collagen 1 (COL1) and aggrecan (ACAN) was evaluated. Immunocytochemical staining of all mentioned proteins was performed to evaluate chondrocyte specific production.

Results. Cartilage specific gene expression of COL2 and ACAN have shown that the proposed protocol leads to isolation of cells with a high chondrogenic potential, possibly even specific phenotype preservation up to the second passage. COL1 expression has confirmed the tendency of the isolated cells dedifferentiation into a fibroblast-like phenotype already in the second passage, which confirms previous findings that higher passages should be used with care in cartilage tissue engineering. To evaluate the effectiveness of our approach, immunocytochemical staining of the evaluated chondrocyte specific products was performed as well.

Discussion. In this study, we developed a protocol for isolation and consequent cultivation of primary human adult articular chondrocytes with the desired phenotype from the surgical waste obtained during TKA. TKA is a common and very frequently performed orthopaedic surgery and relatively cheap isolation of chondrocytes as was confirmed in our study. 


\section{INTRODUCTION}

Damage to articular cartilage has important clinical implications since the cartilage tissue possesses a limited intrinsic healing potential and tends to an incomplete regeneration by local chondrocytes, accompanied with an inferior fibrocartilage formation (Camp et al. 2014; McNickle et al. 2008; Richter et al. 2016). Surgical intervention is often the only option, although the repair of damaged cartilage is often less than satisfactory, and rarely restores full function or returns the tissue to its native state (Kerker et al. 2008; Kock et al. 2012; Tuli et al. 2003). Over the past decade a number of viable options of cartilage regeneration have been introduced into clinical practice (Camarero-Espinosa et al. 2016; Hettrich et al. 2008; Schrobback et al. 2011). Among these, autologous chondrocyte implantation (ACI) seems the most promising since it relies on the use of biodegradable materials that serve as temporary cellcarriers, enabling in vitro cell growth and subsequent implantation into the defective cartilage (Bomer et al. 2016; Niemeyer et al. 2016; Robb et al. 2012).

Tissue engineering of articular cartilage remains challenging due to the specific structure of cartilage tissue, i.e. its multiphasic cellular architecture together with remarkable weight-bearing characteristics (e.g. resistance to mechanical stress and wear) (Kim et al. 2012; Su et al. 2012). Good understanding of the cartilage structure, physiology, and the molecular basis of chondrogenesis is key to in vitro cartilage production, either for use in tissue engineering or clinics (Bhat et al. 2011; Lee et al. 2013; Li et al. 2012). The state-of-the-art concept of in vitro cartilage tissue development combines the use of biocompatible and biodegradable carrier materials, the application of growth factors, the use of different cell types (stem or already differentiated) and different approaches to simulate the native mechanical stimulation (Gardner et al. 2013; Hildner et al. 2011; Khan et al. 2013; Naranda et al. 2016).

More specific challenges of articular cartilage tissue engineering remain the high consumption of cells and related costs, as well as the preparation of an ideal host scaffold. Although solutions to both mentioned challenges have been introduced in recent years (Bassleer et al. 1998; Stellavato et al. 2016), is the cell part gaining far less research momentum. Therefore, it comes to no surprise that novel approaches for chondrocyte isolation are highly desired, especially considering the high prices of ordered cells. Optimisation of isolation yields, abundant cell sources and efficient culturing procedures that lead to preparation of desired, reproducible and relatively affordable cell cultures or/and material-cell constructs with good durability, are therefore highly rated novelties in recent research (Dehne et al. 2009; Naranda et al. 2016; Otero et al. 2012).

Several methods for chondrocyte isolation from various tissue parts and organisms were introduced over the last decades (Hu et al. 2002; Li et al. 2015; Mirando et al. 2014; Shortkroff \& Spector 1999; Strzelczyk et al. 2001; Xu \& Zhang 2014). Although their cell source varies, the crucial steps of these reported isolation protocols have a lot of common ground. One of the main similarities to digest the harvested tissue during the preparation of the primary culture is the use the enzyme type 2 collagenase (Hayman et al. 2006; Lagana et al. 2014). Variations in the time of the tissue exposure to the enzyme (Hayman et al. 2006), as well as combining it with other enzymes (trypsin, pronase, hyaluronidase etc.) is not unusual (Jakob et al. 2001). Several 
examples of effective chondrocyte isolation procedures including the source tissue and organism, the digestion enzyme, time of tissue exposure and the cell yield, were summarized by Oseni et al (Oseni et al. 2013). In their study, Oseni et al. evaluated the necessary isolation and characterization procedures that would give a maximum yield with optimal cell viability for the engineering of large cartilaginous constructs such as the human nose and ear (Oseni et al. 2013). At this point it is important to mention that the state of the source tissue has also to be accounted for (Lagana et al. 2014). In this context, Lagana et al. performed characterization of basic parameters of articular chondrocytes isolated from 211 osteoarthritic patients. They concluded that a systematic characterization of the cellular yield and chondrocyte proliferation rates is very useful in view of a possible autologous cell therapy (Lagana et al. 2014). Therefore, it is very important to determine the quality of the cell source, which is known to greatly influence the outcome of engineered tissue (Lagana et al. 2014).

The most demanding part in the process of in vitro culturing still presents the preservation of the desired phenotype to a high enough passage to yield sufficient cells to perform planned experiments (Pei \& He 2012; Rosenzweig et al. 2012; Schnabel et al. 2002a; Wu et al. 2014). Since the latter depends on numerous factors and can therefore be confirmed only by a combination of (often) expensive techniques (different microscopies, molecular analysis, immunocytochemistry etc.), it is important to prepare protocols for an easier and cheaper preliminary phenotype confirmation by means of methods, available in most cell laboratories around the world. Since the desired phenotype can be identified by chondrocyte specific production (Chen et al. 2014; Han et al. 2010), we believe that the easiest and safest preliminary method to prove phenotype preservation could be the analysis of gene expression. More specifically, this analysis should include the evaluation expression of genes related to cartilage specific markers (e.g. collagen type 2 and aggrecan). To follow-up possible dedifferentiation towards the fibroblastic phenotype (Duan et al. 2015; Goldring et al. 2006; Haudenschild et al. 2001; Makris et al. 2015; Otero et al. 2012), we propose simultaneous measurement of upregulation of collagen type 1 .

Based on all mentioned it is clear that chondrocyte isolation from an abundant source with a high yield, together with an effective and cheap preliminary phenotype confirmation method, would be greatly beneficial to boost the development of cartilage tissue engineering (Cetinkaya et al. 2011; Goepfert et al. 2010; Schrobback et al. 2011). This study was therefore designed to provide a relatively simple, yet effective procedure for isolation and culturing of human tissue derived primary chondrocytes up to the second passage. As the preliminary method of phenotype confirmation, we chose the evaluation of chondrocyte specific gene expression, together with morphological evaluation of cells. Such an approach provides a cheap and effective protocol to be considered an alternative to other available methods (Hu et al. 2002; Li et al. 2015; Strzelczyk et al. 2001; Xu \& Zhang 2014), especially suitable for other laboratories to boost their respective entry level cartilage tissue engineering studies. To confirm our claims and the overall effectiveness of the used approach, immunocytochemical analysis of the most important chondrocyte specific extracellular matrix products (aggrecan and collagen type 2) were evaluated after one week of cell growth (for the second passage). To observe the tendency of the 
140 chondrocyte cells towards differentiation into fibroblast like cells, collagen type 1 was also 141 evaluated using the same approach.

\section{MATERIALS AND METHODS}

\section{$143 \quad 2.1 \quad$ Materials}

144 All used materials and chemicals were of laboratory grade and purchased from Sigma-Aldrich, 145 Germany, if not stated otherwise. For specific parts of the isolation process and cultivation, all 146 used labware and chemicals were additionally sterilized using the standard autoclavation 147 procedure (Avtoklav A-21, Kambič, Slovenia).

\section{$148 \quad 2.2$ Isolation of primary chondrocytes}

149 Full-thickness cartilage was surgically removed from the femoral condyle of arthritic knee of a 15050 years old patient who underwent total knee arthroplasty (TKA) performed at the University 151 Medical Centre Maribor, Slovenia (application reference: 123/05/14). Prior to surgery, no 152 systemic disease or any treatment was reported for the donor patient. The study was conducted in 153 accordance with the Declaration of Helsinki and its subsequent amendments and was approved 154 by the Republic of Slovenia National Medical Ethics Committee (Ljubljana, Slovenia). The 155 patients' written consent was obtained.

156

157

158

159

160

161

162

163

164

165

166

167

168

169

170

171

172

173

174

175

176

177

178

The cartilage tissue was surgically removed under sterile conditions during TKA procedure. The standard cutting blocs for femoral resection were used and resection was performed in the usual manner. Distal and/or posterior femoral condyles were used for chondrocyte isolation depending on the macroscopic condition of the cartilage tissue (due to e.g. osteoarthritis). Immediately after the removal, the bone cuts were transferred into a previously sterilized $250 \mathrm{ml}$ glass bottle filled with phosphate buffered saline (PBS, Sigma-Aldrich, Germany) and immediately brought to the cell isolation laboratory.

The cartilage-bone tissue was transferred to a petri dish filled with PBS to prevent drying of the tissue. In the cell isolation laboratory, the cartilage tissue was carefully removed from the bone cuts surface using a No 11 blade to obtain approximately $2 \times 2 \mathrm{~mm}$ pieces of cartilage tissue. PBS was carefully removed by a pipette and the petri dish was immediately filled with $10 \mathrm{~mL}$ solution of 0.25 wt. $\%$ Trypsin/EDTA (Sigma, France). The as-prepared cartilage pieces were incubated for 3 hours at $37^{\circ} \mathrm{C}$ and 5 wt. $\% \mathrm{CO}_{2}\left(\mathrm{CO}_{2}\right.$ Incubator MCO-19AICUVH-PE, Panasonic, Japan), followed by addition of $20 \mathrm{~mL}$ of Advanced Dulbecco's modified Eagle's medium (Advanced DMEM, Gibco, Grand Island, NY, USA) to the cell suspension. The suspension was transferred to a $50 \mathrm{~mL}$ falcon tube and centrifuged at $300 \mathrm{x}$ g for 10 minutes (Centrifuge 5804 R, Eppendorf, USA). The supernatant was carefully discarded and the cell pellet was re-suspended in $20 \mathrm{~mL}$ of Advanced DMEM and centrifuged at $200 \mathrm{x}$ g for 5 minutes (Centrifuge 5804 R, Eppendorf, USA). The supernatant was again carefully discarded and the cell pellet re-suspended in $10 \mathrm{~mL}$ Advanced DMEM supplemented with $100 \mathrm{IU} / \mathrm{ml}$ Penicillin, 1 $\mathrm{mg} / \mathrm{ml}$ Streptomycin, $2 \mathrm{mM}$ L-glutamine and $5 \mathrm{wt} . \%$ foetal bovine serum (FBS, Gibco, Grand Island, NY, USA) and plated on $25 \mathrm{~cm}^{2}$ flasks (in triplicates). In the cell pellet, very small fragments of cartilage were also present. Besides primary chondrocytes, these fragments were 
179 also seeded and after a week of incubation, the cells were observed crawling from the tissue 180 fragments. Together with the primary chondrocytes these were then left until confluence was 181 reached.

182 Growing cells were regularly observed with an Axiovert 40 inverted optical microscope (Zeiss, 183 Germany) at several magnifications. The culturing medium was changed every three days. The 184 general steps of the procedure are schematically depicted in Fig. 1.

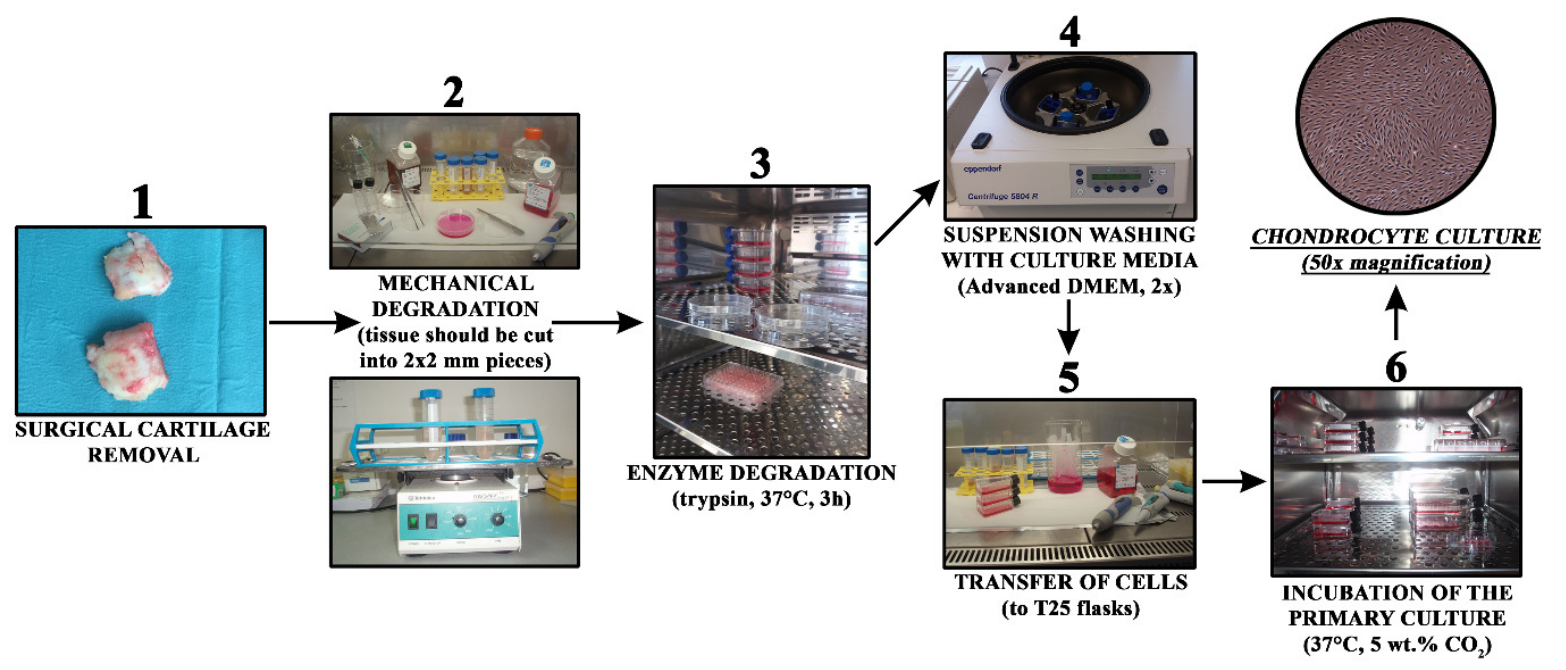

Fig. 1: Chondrocyte isolation from cartilage in a short overview of the most important preparation steps.

185

186

187

188

189

190

191

192

193

194

195

196

197

198

199

200

201

202

203

204

\subsection{Gene expression analysis}

Gene expression analysis of cartilage specific markers collagen type 2 (COL2) and aggrecan (ACAN) was performed in order to determine the primary chondrogenic phenotype. Possible dedifferentiation to a more fibroblast like cell type was evaluated by monitoring the expression of collagen type 1 (COL1). After confluence was reached in all respective samples (triplicates) (see above section 2.2. for details), the cell suspension was transferred to micro-centrifuge tubes, and $1.4 \mathrm{~mL}$ of TRI reagent (Sigma-Aldrich, Germany) was added. The tubes were vortexed for $30 \mathrm{~min}$ at room temperature. Afterwards, $280 \mu \mathrm{L}$ of chloroform (Sigma-Aldrich, Germany) was added and the tubes were further vortexed for $15 \mathrm{~min}$ and centrifuged at $12.000 \mathrm{rpm}$ and $4{ }^{\circ} \mathrm{C}$. RNA extraction was carried out according to the manufacturer's instructions (Chomczynski 1993; Louveau et al. 1991). Concentration and purity of the extracted cellular RNA was determined using NanoDrop 2000c (Thermo Scientific, Delaware, USA) through optical density readings at $260 \mathrm{~nm}$ and a 260/280 $\mathrm{nm}$ ratio. cDNA was obtained by using a cDNA reverse transcription kit (Applied Biosystems, California, USA). Primer sequences for cartilage target genes ACAN and COL2 were obtained from Caterson et al. (Caterson et al. 2001), while the corresponding mRNA sequences were retrieved from PubMed Nucleotide database (www.ncbi.nlm.nih.gov/nuccore/) and the AceView database (Thierry-Mieg \& Thierry-Mieg 2006). Primers for the target gene COL1 were designed using IDT oligo analyser (eu.idtdna.com/calc/analyzer). The primer sequences with the corresponding mRNA sequences and the corresponding NCBI accession numbers, are given in Table 1. $2 \mu \mathrm{L}$ of each cDNA 
205

206

207

208

209

210

211

212

sample with concentration of $15 \mathrm{ng} / \mu \mathrm{L}$ was used for quantitative real time PCR (qPCR) analysis performed using LightCycler 480 thermocycler (Roche, Switzerland) and with $2 \times$ Maxima SYBR Green qPCR master mix (Life Technologies, California, USA) according to the manufacturer's instructions. The quality and specificity of PCR amplicons were checked using melting curve analyses and agarose gel electrophoresis. All shown results are presented as average values with the standard errors.

Table 1: Primer sequences with the corresponding mRNA sequence and the corresponding NCBI accession numbers.

\begin{tabular}{|c|c|c|c|}
\hline Gene & Gene name & $\begin{array}{l}\text { Accession } \\
\text { number }\end{array}$ & Primer sequence $5^{\prime} \rightarrow 3^{\prime}$ \\
\hline \multirow{2}{*}{$A C A N$} & \multirow{2}{*}{ Aggrecan } & NM_013227.3 & TGAGGAGGGCTGGAACAAGTACC \\
\hline & & NM_001135.3 & GGAGGTGGTAATTGCAGGGAACA \\
\hline \multirow{2}{*}{ COL1 } & \multirow{2}{*}{$\begin{array}{l}\text { Collagen type } 1 \text {, alpha } \\
1\end{array}$} & \multirow{2}{*}{ NM_000088.3 } & CGGCTCCTGCTCCTCTTAG \\
\hline & & & CACACGTCTCGGTCATGGTA \\
\hline \multirow{2}{*}{ COL2 } & \multirow{2}{*}{$\begin{array}{l}\text { Collagen type } 2 \text {, alpha } \\
1\end{array}$} & NM_001844.4 & TTTCCCAGGTCAAGATGGTC \\
\hline & & NM_033150.2 & CTGCAGCACCTGTCTCACCA \\
\hline GAPDH & $\begin{array}{l}\text { Glyceraldehyde-3- } \\
\text { phosphate } \\
\text { dehydrogenase }\end{array}$ & $\begin{array}{l}\text { NM_001289745.1 } \\
\text { NM_002046.5 } \\
\text { NM_001289746.1 } \\
\text { NM_001256799.2 }\end{array}$ & $\begin{array}{l}\text { GGGCTGCTTTTAACTCTGGT } \\
\text { TGGCAGGTTTTTCTAGACGG }\end{array}$ \\
\hline
\end{tabular}

\subsection{Immunocytochemistry}

214

215

216

217

218

219

220

221

222

223

224

225

226

227

228

229

230

231

232

233

We characterized cells according to the expression of specific surface proteins (COL1, COL2, ACAN). Additional staining was performed in order to analyse the cells' general morphology (cytoskeleton (actin) - using Phalloidin - iFluor 555 Reagent (Abcam, UK); nucleus - using mounting medium with 4',6-diamidino-2-phenylindole (DAPI, Sigma-Aldrich, Germany)). Some more details about respective methods are described below. All micrographs were taken using either Floid Cell Imaging Station (Thermo Fisher Scientific, USA) or EVOS FL Cell Imaging System (Thermo Fisher Scientific, USA).

\subsubsection{General protocol for immunocytochemistry}

Round glass slides $(2 \mathrm{r}=12 \mathrm{~mm})$ were placed on the bottom of wells in a P24 plate (in triplicate for each used dye) similar to the procedure used by Oseni et al. (Oseni et al. 2013). Isolated cells (from the second passage) at a density of 50,000 cells / well were placed on each of the glass slides and incubated at $37{ }^{\circ} \mathrm{C}, 5$ wt. $\% \mathrm{CO}_{2}$ for 7 days. The medium (Advanced DMEM, supplemented with foetal bovine serum (FBS, Gibco, Grand Island, NY, USA)) was removed and the cells were washed with phosphate buffered saline (PBS, Sigma-Aldrich, Germany) once. Fixation of cells was performed using the Fixation Solution (Millipore, USA) for 10 minutes at room temperature, followed by washing of the cells three times with cold $\operatorname{PBS}\left(\sim 4{ }^{\circ} \mathrm{C}\right)$.

Further sample handling differed for respective staining procedures. Namely, ACAN, COL1 and COL2 were stained using primary and secondary antibodies (the manufacturers protocols were followed for this purpose), whereas actin was stained in a single step (again, according to the manufacturers protocol). 
234

235

236

237

238

239

240

241

242

243

244

245

246

247

248

249

250

251

252

253

254

255

256

257

258

259

260

261

262

263

264

265

266

267

268

269

\subsubsection{Actin staining}

Following the general protocol for immunocytochemistry, the working solution of the conjugated Phalloidin (1000x Phalloidin stock solution in dimethyl sulfoxide DMSO (Abcam, UK), 1/1000 dilution in PBS with 1 wt.\% bovine serum albumin (BSA, Sigma-Aldrich, Germany) and 0.1 wt.\% Tween 20 (Sigma-Aldrich, Germany)) was added. Incubation was performed for 90 minutes at room temperature and in a dark room. Rinsing was performed with PBS and was repeated three times. The final step was the addition of the Fluoroshield Mounting Medium with DAPI. Micrographs were taken at the suitable wavelengths for respective used dyes (excitation/emission: DAPI=306/460 $\mathrm{nm}$ and Phalloidin=556/574 nm).

\subsubsection{Staining of COL1, COL2 and ACAN}

Following the general protocol for immunocytochemistry described above, the cells were incubated for 30 minutes with PBS, supplemented with $1 \mathrm{wt} . \%$ BSA and $0.1 \mathrm{wt} . \%$ solution of Tween 20 to block nonspecific binding of antibodies. All incubations with the primary antibodies was performed overnight at $4{ }^{\circ} \mathrm{C}$. Respective dilutions (in PBS with $1 \mathrm{wt} . \%$ BSA and $0.1 \mathrm{wt} . \%$ solution of Tween 20) of the primary antibodies were as follows:

1. ACAN: Anti-Aggrecan antibody [6-B-4] (Abcam, UK), 1:50,

2. COL2: Anti-Collagen 2 antibody (Abcam, UK), 1: 200,

3. COL1: Anti-Collagen 1 antibody (Abcam, UK), 1: 500.

After incubation, the cells were washed three times with PBS for 5 minutes. Incubation of cells with the secondary antibodies was performed in a dark at room temperature for 1 hour (the same procedure was used also as the control for the attachment of respective secondary antibodies). The dilutions of the secondary antibodies (in PBS with $1 \mathrm{wt} . \%$ BSA and $0.1 \mathrm{wt} . \%$ solution of Tween 20) were as follows:

1. ACAN: Rabbit Anti-Mouse IgG H \& L (Alexa Fluor 488) preabsorbed (Abcam, UK), 1: 1000 ,

2. COL2 and COL1: Goat anti-rabbit IgG H \& L (Alexa Fluor 594) (Abcam, UK), 1: 1000.

After incubation, the cells were washed three times with PBS for 5 minutes. Finally, three drops of the Mounting Medium Fluoroshield with DAPI were added and the solution was left on the cells for 5 minutes. Micrographs were taken at the suitable wavelengths for respective used dyes (excitation/emission: $\mathrm{ACAN}=495 / 519 \mathrm{~nm}$ and COL2/COL1 $=590 / 617 \mathrm{~nm}$ ).

\section{RESULTS}

\subsection{Isolation of primary chondrocytes}

As mentioned in the Materials and methods section, the full-thickness cartilage was obtained from the femoral condyle of an arthritic knee during knee arthroplasty (TKA) performed at the University Medical Centre Maribor, Slovenia. TKA is a common procedure at the mentioned hospital, considering that approximately 700 such surgeries are performed each year 
270 (Univerzitetni klinicni center 2014). Since the removed cartilage tissue is considered surgical waste, this presents a reliable and continuous source for isolation of primary chondrocytes.

272 The primary chondrocytes were isolated as described in the Materials and methods section. 273 During their cultivation, their morphology and proliferation were regularly observed using 274 inverted optical microscopy (Fig. 2). Fig. 2A shows the thin slice of cartilage that was used for 275 their cultivation, while Fig. 2B-D present the primary human chondrocytes in a monolayer 276 culture at different cultivation times. This initial examination was performed to follow possible 277 morphological changes in the cell shapes, which would indicate possible dedifferentiation.
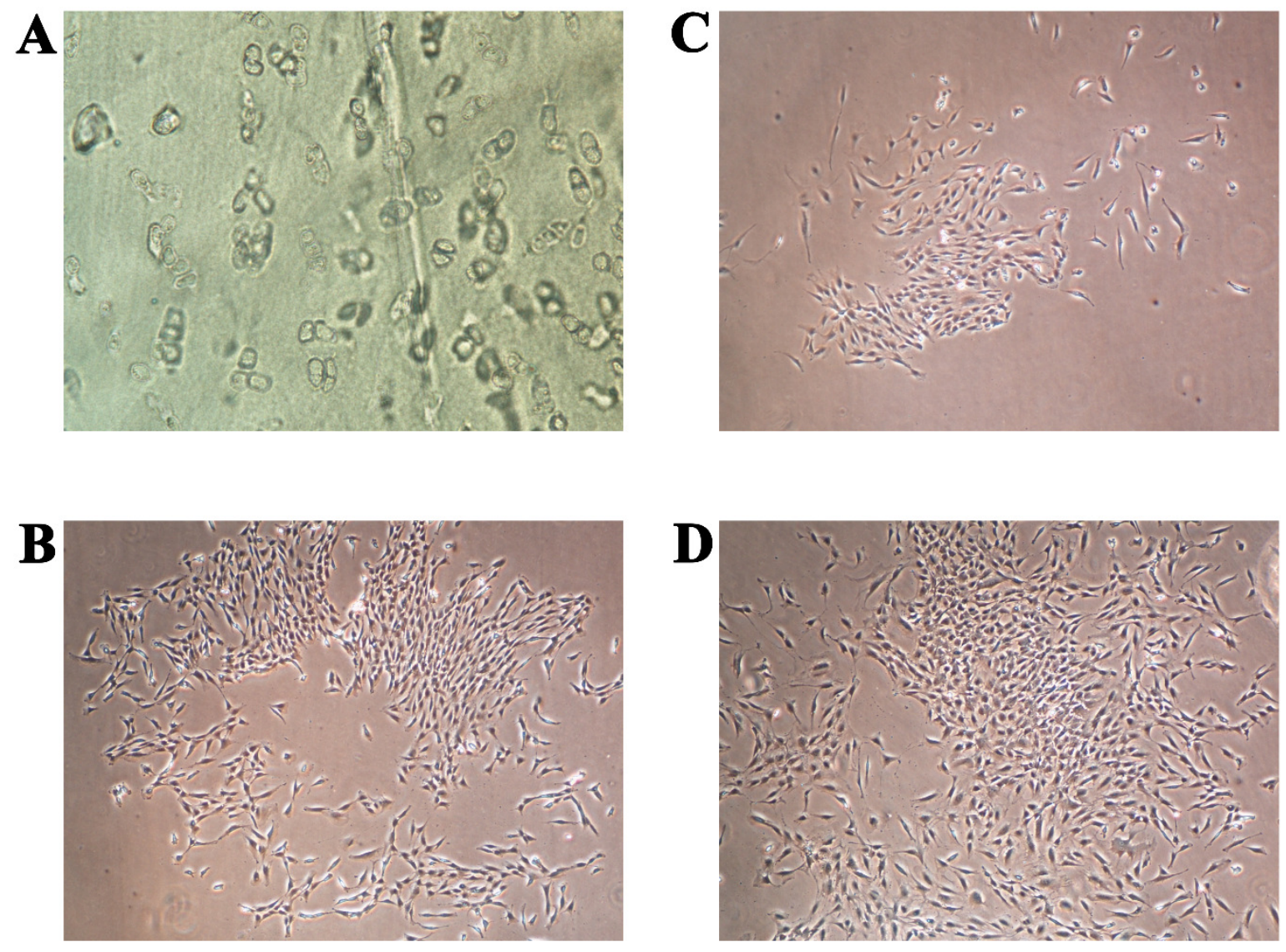

Fig. 2: A) Thin slice of cartilage for primary chondrocyte isolation; B-D) the primary human chondrocyte culture in a monolayer after 3,6 and 9 days, respectively. The magnification of all shown images is 50x.

278 The full confluence of the isolated cells for the first and second passage was reached after two 279 (14 days) and after one (7 days) week, respectively. Cell growth stopped presumably due to contact inhibition (Lackie 2013). A comparison between the primary chondrocyte culture and the obtained chondrocyte cultures after the first and second passages, is shown in Fig. 3. The cells formed confluent monolayers (after the above mentioned cultivation times) and appeared polygonal in shape (Fig. 3A-C). It can be observed that the chondrocyte morphology became more spindle-like in the second passage (Fig. 3C), showing their tendency for dedifferentiation, 285 most likely towards fibroblast like cells (Hong \& Reddi 2013). Observing the mentioned changes 
286 was an indication that the third passage will not yield a high percentage of chondrocytes only, 287 using the proposed cultivation conditions.
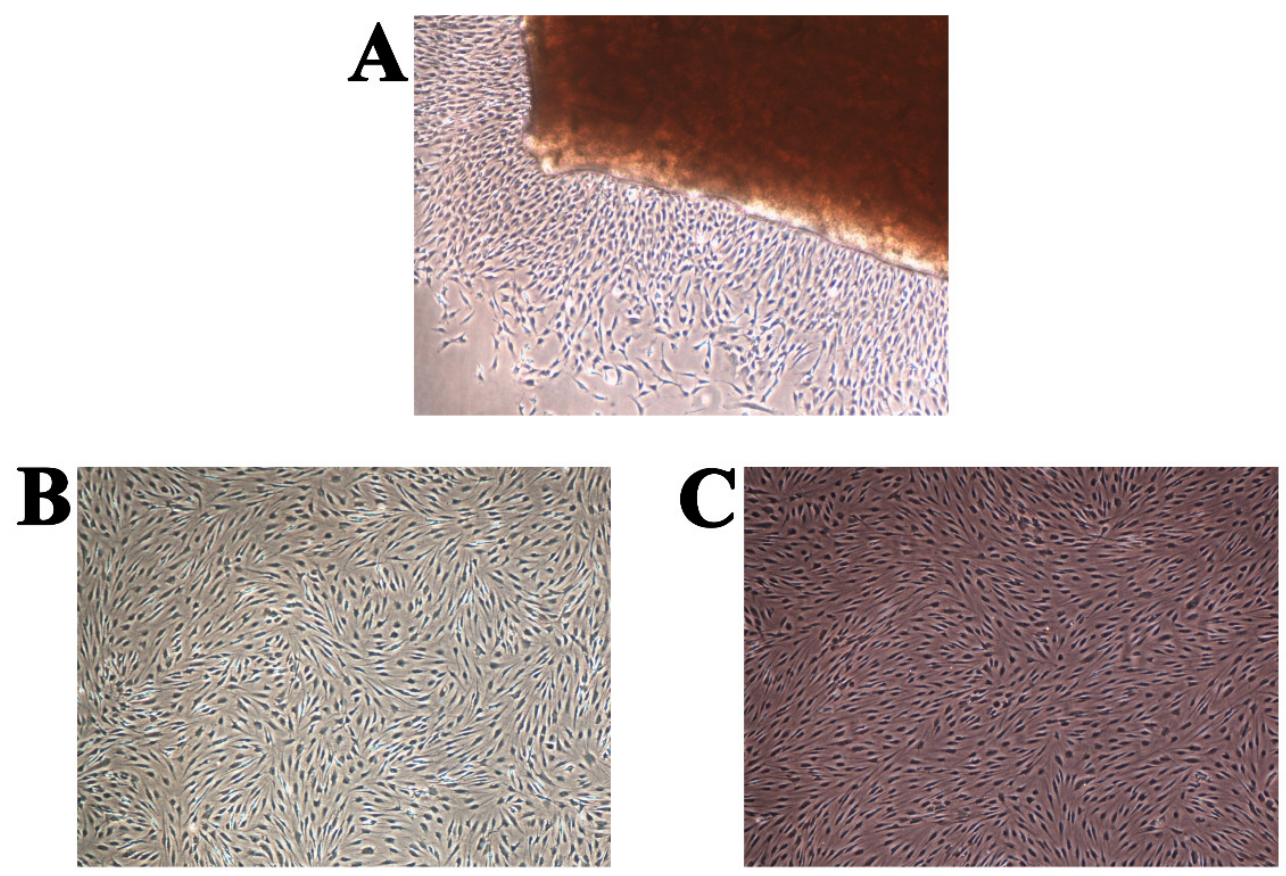

Fig. 3: Human chondrocyte culture: A) the explant culture of chondrocytes ("primary culture"), B) monolayer of chondrocytes after first passage, and C) monolayer of chondrocytes after the second passage. The magnification of all shown images is $50 \mathrm{x}$ (the inlay images were taken with a magnification of 100x).

\section{$288 \quad 3.2$ Gene expression analysis of the isolated chondrocytes}

289 Now that we determined the suitable number of passages presumably yielding a high percentage 290 of chondrocyte cells, we performed additional characterization to confirm the chondrocytes' 291 desired phenotype. Analysis of gene expression was chosen due to its affordability and 292 availability. The isolated cells from the human articular cartilage were characterized in regard of 293 the genes related to specific chondrogenic production, namely collagen type 2 (COL2) and 294 aggrecan (ACAN). To detect possible dedifferentiation towards fibroblast like cells, expression of collagen type 1 (COL1) was also determined. Expression of all three mentioned genes was performed after the confluence was reached for the second passage (after 7 days). As shown in

297 Fig. 4 and Fig. 5, both cartilage specific genes (COL2 and ACAN) and also the marker of 298 fibrocartilage (COL1) were expressed in the isolated chondrocytes in both passages. qPCR 299 results are presented as absolute $\mathrm{Ct}$ values. Reference gene GAPDH was used as an internal 300 control (Chen et al. 2016). 


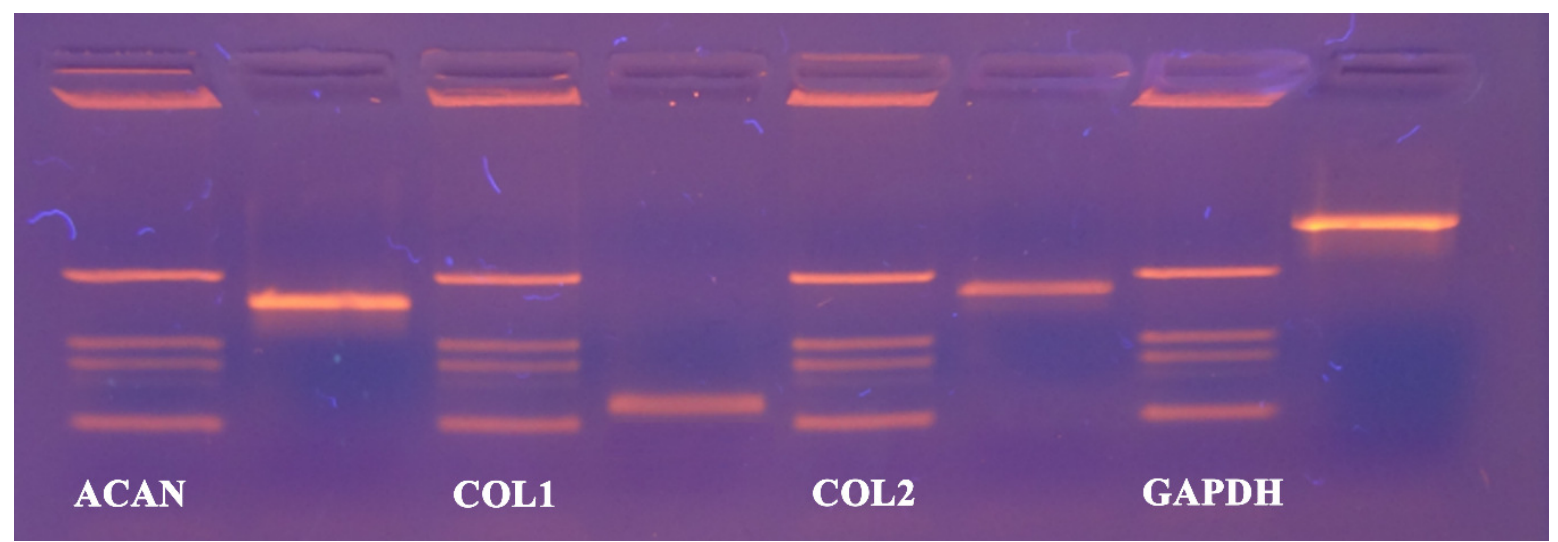

Fig. 4: cDNA products of analysed genes (GAPDH, collagen type 1, collagen type 2 and aggrecan) at the end-point of qPCR on agarose gel electrophoresis.

Analyzed genes: GAPDH (702 bp), COL2 (377 bp), COL1 (137 bp), ACAN (350 bp) and DNA markers (433 bp, 245 bp, 203 bp, 114 bp).

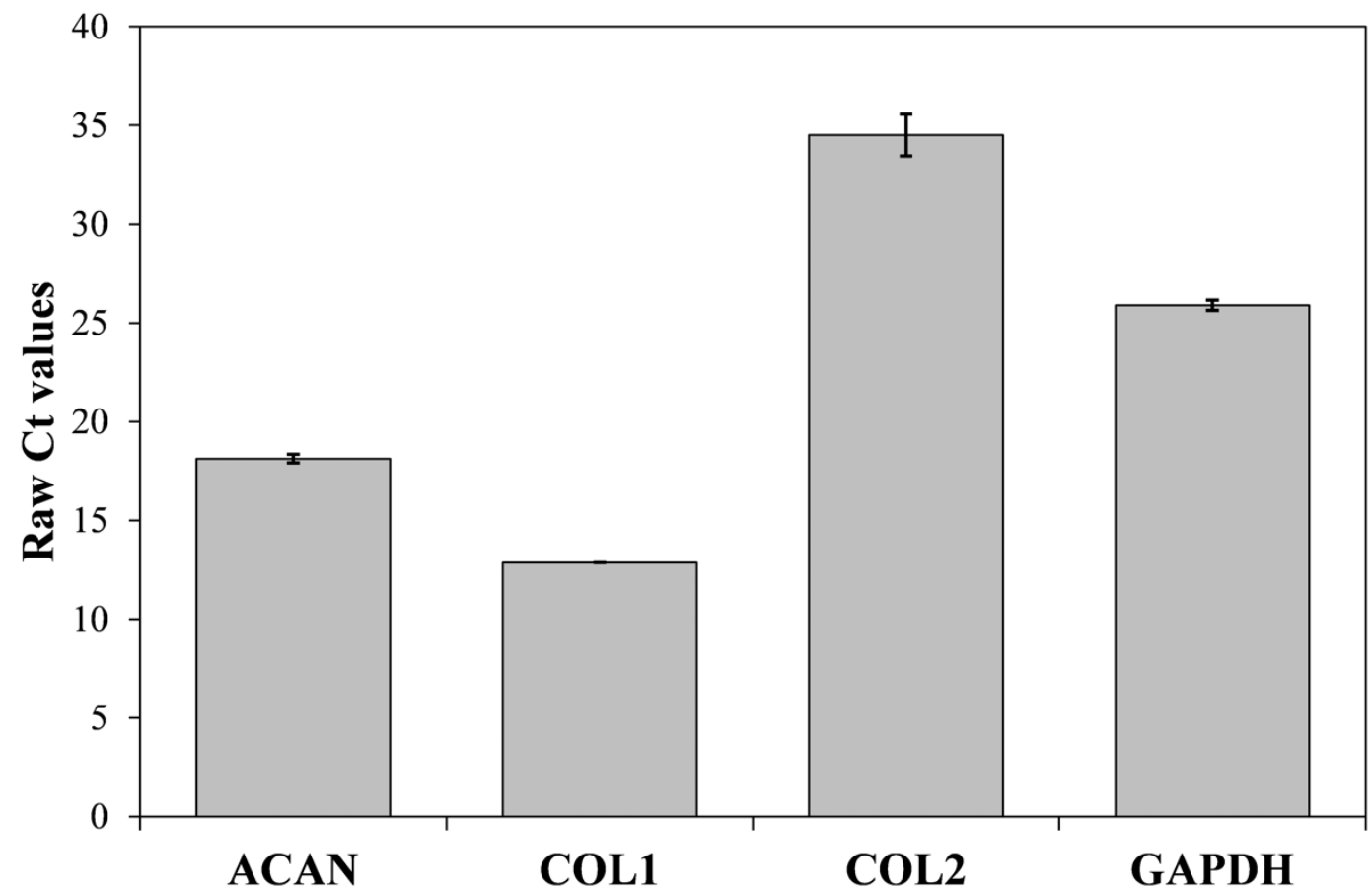

Fig. 5: Results of qPCR analysis presented as absolute $\mathrm{Ct}$ values of target genes expression (ACAN, COL1, COL2 and GADPH). The results are presented as average values with the standard errors of a triplicate.

\subsection{Immunocytochemistry}

302 We performed immunocytochemistry on the isolated cells to investigate chondrocyte phenotype 303 alterations (ACAN, COL1 and COL2). Additionally, the cytoskeleton (actin) and cell nucleus 304 were stained to show the overall healthy morphology of the cells. All staining was performed in 305 three repetitions. As the negative control, staining only with the respective secondary antibodies, 306 as well as with the Mounting medium with DAPI (after one day and after two days), were used. 307 Production of all three proteins was confirmed (Fig. 6 A-C), which is in agreement with the 
308 results from the molecular analysis. All negative controls have shown no fluorescence, 309 confirming the effectiveness and specificity of the used protocols. Staining of actin (Fig. 6 D) 310 confirmed the expected morphology of healthy cells, which is in agreement with the micrographs 311 using optical microscopy.
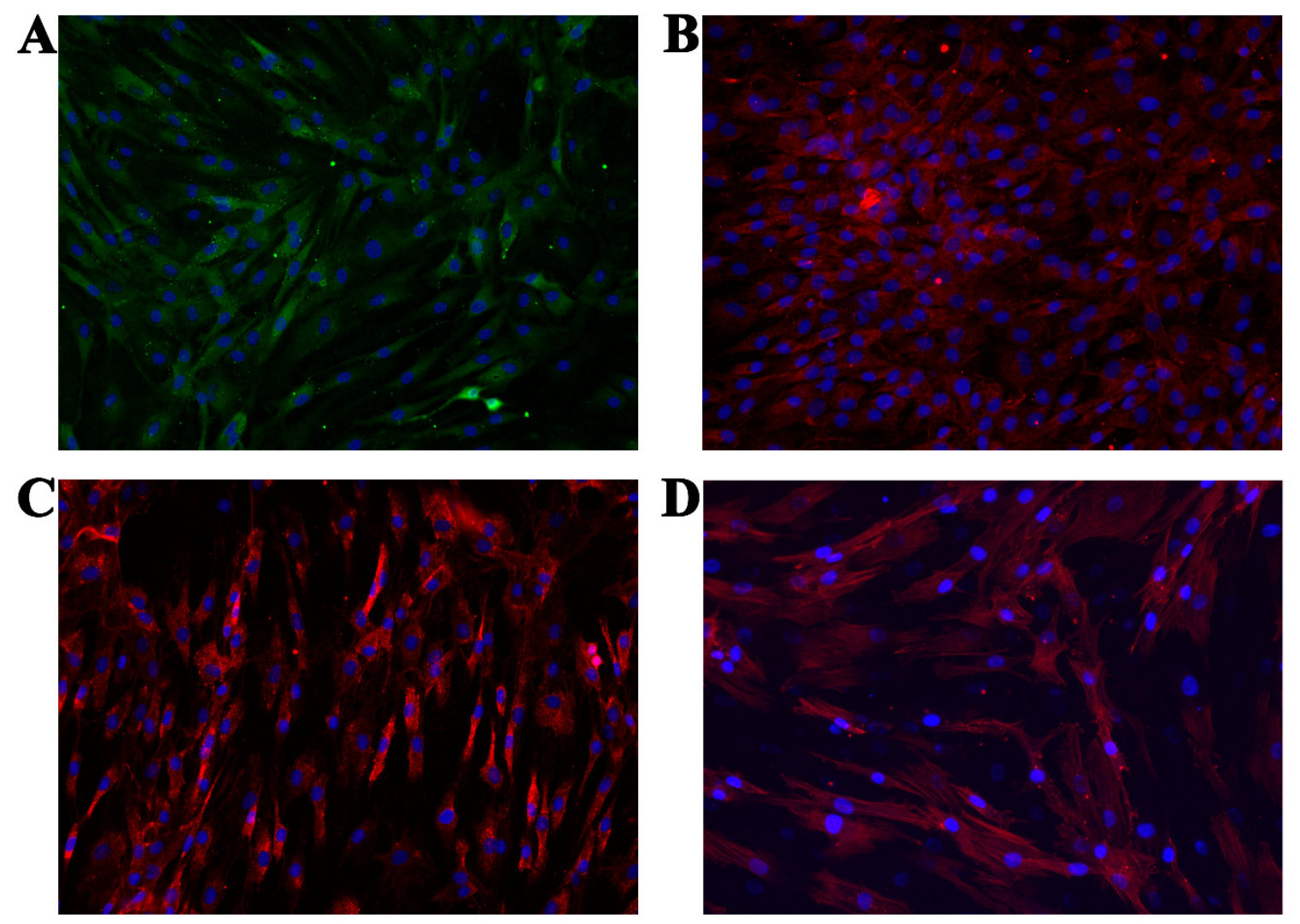

Fig. 6: Micrographs of the stained samples: A) for ACAN, B) for COL2 and C) COL1. Additionally, D) shows the cells with a stained cytoskeleton (actin). For all samples a mounting medium with DAPI was used to stain the nuclei. The magnification of all shown images is 460x (according to the manufacturers microscope specifications).

\section{DISCUSSION}

314 The development of novel solutions related to any tissue engineering application consumes a 315 huge number of cells to prove safety and efficiency (Groeber et al. 2012; Maver et al. 2015; 316 Mohd Hilmi \& Halim 2015; Rodriguez-Vazquez et al. 2015). Cartilage tissue engineering is no 317 exception, and hence large scale expansion of chondrocytes is required either for novel scaffold 318 testing, determination of potential cytotoxic effects of medical devices and implants for 319 orthopaedic use (Bomer et al. 2016; Camarero-Espinosa et al. 2016; Makris et al. 2015). 320 Cultivation of such high cell counts is a demanding task, especially considering the low number 321 of obtained cells in the primary culture, and an often limited amount of available tissue.

322 Consequently, further expansion and consecutive passages are needed, which on the other hand 323 can lead to dedifferentiation (Mirando et al. 2014; Shortkroff \& Spector 1999; Thirion \& 
324 Berenbaum 2004). The latter is evident by morphological changes of the cells from polygonal to

325

326

327

328

329

330

331

332

333

334

335

336

337

338

339

340

341

342

343

344

345

346

347

348

349

350

351

352

353

354

355

356

357

358

359

360

361

362

363

364

365 more elongated, as well as through a reduction in the growth rate (Cetinkaya et al. 2011; Haudenschild et al. 2001; Otero et al. 2012). For example, development of novel scaffolds for cartilage tissue engineering often requires a million cells per sample scaffold (the number depends on the size of the scaffold to be tested), exposing the high demand for cells and at the same time one of the major bottlenecks in development of novel tissue engineering solutions. At later passages, the quality of chondrocytes gradually decreases and is characterized with many of the phenotypic traits of fibroblast like cells and an increased synthesis of collagen type 1, rather than type 2 (Bonaventure et al. 1994; Diekman et al. 2009; Schnabel et al. 2002b).

A sufficient number of cells can be ensured either through significant expenses (purchase of cells from different cell banks) or isolation of desired cells from tissues. While the first scenario requires sufficient funds, the latter requires appropriate tissue sources, an approval of respective Committees of Medical Ethics, and a rigorous final analysis to confirm the isolation of the desired cell type only. Since we work in the close proximity and in tight collaboration with the local University Medical Centre, the second scenario was more convenient. Our goal was to prepare a simpler and generally available protocol, which would include the isolation of primary chondrocytes from full-thickness cartilage that is surgically removed from the femoral condyle of an arthritic knee during total knee arthroplasty (TKA). As a preliminary prove of the protocols' efficiency, we considered gene expression analysis as the best option, since it is affordable and the required instrumentation (PCR, inverted optical microscope) is most likely available in most cell biology laboratories. The set of analysed genes was carefully chosen considering the available literature to monitor cartilage phenotype alterations (Caterson et al. 2001; Diekman et al. 2010; Grogan et al. 2014; Jonitz et al. 2012; Seda Tigli et al. 2009; Shi et al. 2014). Based on the mentioned, the correlation between COL2 and COL1 in addition to ACAN, seemed to be the most suitable. For confirmation of the effectiveness of the proposed approach in terms of chondrocyte specific production besides the gene expression, immunocytochemical staining of COL2, COL1 and ACAN was used as well. The latter confirmed the chondrocyte specific productions (ACAN and COL2), as well as the presence of COL1, which could be an indication of ongoing dedifferentiation to more fibroblast like cells.

In general, the chondrocyte isolation protocol can be divided into different stages: isolation, seeding and chondrocytes grow in culture, although description and number of steps can vary (Gosset et al. 2008; Thirion \& Berenbaum 2004). After initial plating of the primary cultures, the chondrocytes spread out after 2-3 days and after 4-7 days the sufficient amounts of total RNA may be extracted. Primary cartilage phenotype (often confirmed by evaluating the presence of COL2 and ACAN mRNAs) may be initially preserved, but the expression of nonspecific collagens (e.g. COL1) begins to appear already 7 days after isolation (Otero et al. 2005). Moreover, adult articular chondrocytes are strongly contact-inhibited and undergo a rapid change in phenotype and gene expression, termed "dedifferentiation", when isolated from cartilage tissue and cultured on culturing plastics (Haudenschild et al. 2001). Therefore, primary chondrocyte cultures should be used for experimental analyses immediately before or just after confluence is reached to assure optimal matrix synthesis and cellular responsiveness (Schneevoigt et al. 2016). 
366

367

368

369

370

371

372

373

374

375

376

377

378

379

380

381

382

383

384

385

386

387

388

389

390

391

392

393

394

395

396

397

398

399

400

401

402

403

404

405

406

407

408

In the last two decades, several chondrocyte isolation protocols were developed and reported on (Hayman et al. 2006; Hu et al. 2002; Jakob et al. 2001; Lagana et al. 2014; Oseni et al. 2013; Strzelczyk et al. 2001). For example, an important recent study was conducted by Lagana et al (Lagana et al. 2014), who isolated chondrocytes from 211 osteoarthritic (OA) patients undergoing total joint replacement. The authors of this study analysed specific features of chondrocytes such as cellular yield, cell doubling rate and the dependence between these parameters and patient-related data (e.g. joint type, age and gender). They concluded that such a systematic characterization of important cell source parameters could be useful in view of a possible autologous cell therapy for osteoarthritis, since the cell source quality is known to greatly influence the outcome of engineered tissue (Lagana et al. 2014). Another crucial study that we studied in details prior to our experimental design, was performed by Oseni et al. (Oseni et al. 2013). In this study, the authors focused on a very important factor related to possible clinical use of cartilage tissue engineered products, namely the optimization of the isolation protocol to allow for a large-scale production. The result of their study was an optimized protocol with exactly defined isolation parameters (e.g. enzyme and concentration to be used, time of digestion and the seeding density for tissue culturing). Two other studies have to be mentioned in this context as well. Namely, the studies from Jakob et al. (Jakob et al. 2001) and Hayman (Hayman et al. 2006), respectively. Jakob et al. focused on the research of possible chondrocyte isolation yield improvement by using various combinations of enzymes and reagents. Their results indicated that chondrocyte yields and capacity to attach and proliferate are not highly sensitive to the specific isolation protocol used (Jakob et al. 2001). Finally, Hayman et al. conducted a study, in which they tested combinations of 3 different enzymes and variable incubation/digestion times. A very important discussion point raised by the authors of this study was that different isolation protocols are to be used, if the focus is only on the yield or the goal is to produce preferentially "native" chondrocytes (Hayman et al. 2006).

The protocol of chondrocyte isolation described in this article led to successful growth and proliferation of cells with a proven chondrogenic potential up to the second passage as shown using molecular and immunocytochemical analysis. The characterization of primary human chondrocytes by molecular analysis showed the expression of cartilage specific genes (COL2 and ACAN), as well as a sign of dedifferentiation towards fibrocartilage for the second passage (indicated by the expression of COL1). In comparison with other available chondrocyte isolation protocols, we introduced some changes to the general protocol. As mentioned before, our target was a simple protocol with a high enough yield to conduct preliminary cartilage tissue engineering experiment, like testing of suitability of novel materials (Naranda et al. 2016). According to previous studies, the most commonly used enzyme in chondrocyte isolation, is type 2 collagenase (Hayman et al. 2006; Lagana et al. 2014; Oseni et al. 2013). Various incubation times are used to allow for tissue digestion, but in our experience, longer enzyme exposure times of tissues (and with longer exposures, an increasing number of cells as well) often lead to an increased number of dead cells and/or a lower yield of the cells with a desired phenotype. Considering all mentioned, we used a Trypsin/EDTA combination and an incubation time of $3 \mathrm{~h}$. Although this is not the first research study reporting the use of trypsin for chondrocyte isolation (Hidvegi et al. 2006; Jakob et al. 2001), it is the only one to the best of our knowledge, to use only this enzyme during the isolation protocol. Also, the reported incubation time is different to 
409 the mentioned studies. In addition, our protocol does not include the use of any growth factors 410 like reported in some studies (Lagana et al. 2014), again with the focus to simplify the overall 411 protocol. Moreover, no enzyme predigestion step was introduced in our protocol, like in some 412 studies (Oseni et al. 2013).

413 The purpose of our study was not to revolutionize the chondrocyte isolation procedures, but 414 rather to push the evolution of cartilage tissue engineering. As such, our desire was to present an 415 alternative, affordable and relatively simple approach of chondrocyte isolation, especially 416 suitable for laboratories working closely together with orthopaedic clinics. Such laboratories 417 have the unique opportunity to use surgical waste materials, occurring during TKA. Since TKA 418 is a very common surgery (considering the present demographics, the incidence will only 419 increase (Peterson et al. 2015)), this approach could make cartilage related studies far more 420 available also for laboratories with limited resources, and hence push the overall development of 421 this field towards novel and cheaper therapeutic solutions. Based on our results, we can claim 422 that the combination of the use of surgical waste tissue occurring during TKA, and analysis by 423 inverted optical microscopy and chondrocyte specific gene expression, as well confirmation of 424 chondrocyte specific production, indeed results in an alternative and affordable means to boost 425 cartilage related research in the future.

426

427

428

429

430

431

432

433

434

435

436

437

438

\section{CONCLUSION}

In this study, we describe a simple and affordable procedure of isolation and cultivation of human articular chondrocytes demonstrated a high chondrogenic potential to the second passage. As the source material, we propose the surgical waste tissue occurring during total knee arthroplasty (TKA). Chondrocyte cells are crucial not only for development of therapeutic approaches in cartilage repair (e.g. autologous chondrocyte implantation - ACI), but are necessary in cartilage tissue engineering to allow the development of functional cell models and novel scaffolds. For this purpose, chondrocytes have to be isolated in sufficient quantities and their phenotype should be preserved. Since all mentioned is related to very high costs, we propose alternative isolation and testing protocols that are cheaper and could especially boost the preliminary studies related to cartilage research. 


\section{REFERENCES}

440

441

442

443

444

445

446

447

448

449

450

451

452

453

454

455

456

457

458

459

460

461

462

463

464

465

466

467

468

469

470

471

472

473

474

475

476

477

478

479

480

481

482

483

484

485

486

487

Bassleer C, Rovati L, and Franchimont P. 1998. Stimulation of proteoglycan production by glucosamine sulfate in chondrocytes isolated from human osteoarthritic articular cartilage in vitro. Osteoarthritis Cartilage 6:427-434. 10.1053/joca.1998.0146

Bhat S, Tripathi A, and Kumar A. 2011. Supermacroprous chitosan-agarose-gelatin cryogels: in vitro characterization and in vivo assessment for cartilage tissue engineering. $J R$ Soc Interface 8:540554. 10.1098/rsif.2010.0455

Bomer N, Hollander Wd, Suchiman H, Houtman E, Slieker RC, Heijmans BT, Slagboom PE, Nelissen RGHH, Ramos YFM, and Meulenbelt I. 2016. Neo-cartilage engineered from primary chondrocytes is epigenetically similar to autologous cartilage, in contrast to using mesenchymal stem cells. Osteoarthritis Cartilage. 10.1016/j.joca.2016.03.009

Bonaventure J, Kadhom N, Cohen-Solal L, Ng KH, Bourguignon J, Lasselin C, and Freisinger P. 1994. Reexpression of cartilage-specific genes by dedifferentiated human articular chondrocytes cultured in alginate beads. Exp Cell Res 212:97-104. 10.1006/excr.1994.1123

Camarero-Espinosa S, Rothen-Rutishauser B, Foster EJ, and Weder C. 2016. Articular cartilage: from formation to tissue engineering. Biomaterials science. 10.1039/c6bm00068a

Camp CL, Stuart MJ, and Krych AJ. 2014. Current Concepts of Articular Cartilage Restoration Techniques in the Knee. Sports Health 6:265-273. 10.1177/1941738113508917

Caterson EJ, Nesti LJ, Li W-J, Danielson KG, Albert TJ, Vaccaro AR, and Tuan RS. 2001. Threedimensional cartilage formation by bone marrow-derived cells seeded in polylactide/alginate amalgam. Journal of Biomedical Materials Research 57:394-403. 10.1002/10974636(20011205)57:3<394::AID-JBM1182>3.0.CO;2-9

Cetinkaya G, Kahraman AS, Gümüşderelioğlu M, Arat S, and Onur MA. 2011. Derivation, characterization and expansion of fetal chondrocytes on different microcarriers. Cytotechnology 63:633-643. 10.1007/s10616-011-9380-7

Chen JL, Duan L, Zhu W, Xiong J, and Wang D. 2014. Extracellular matrix production in vitro in cartilage tissue engineering. J Transl Med 12:88. 10.1186/1479-5876-12-88

Chen Z, Wei J, Zhu J, Liu W, Cui J, Li H, and Chen F. 2016. Chm-1 gene-modified bone marrow mesenchymal stem cells maintain the chondrogenic phenotype of tissue-engineered cartilage. Stem Cell Res Ther 7:70. 10.1186/s13287-016-0328-x

Chomczynski P. 1993. A reagent for the single-step simultaneous isolation of RNA, DNA and proteins from cell and tissue samples. Biotechniques 15:532-534, 536-537.

Dehne T, Karlsson C, Ringe J, Sittinger M, and Lindahl A. 2009. Chondrogenic differentiation potential of osteoarthritic chondrocytes and their possible use in matrix-associated autologous chondrocyte transplantation. Arthritis Res Ther 11:R133. 10.1186/ar2800

Diekman BO, Rowland CR, Lennon DP, Caplan AI, and Guilak F. 2009. Chondrogenesis of Adult Stem Cells from Adipose Tissue and Bone Marrow: Induction by Growth Factors and CartilageDerived Matrix. Tissue Engineering Part A 16:523-533. 10.1089/ten.tea.2009.0398

Diekman BO, Rowland CR, Lennon DP, Caplan AI, and Guilak F. 2010. Chondrogenesis of adult stem cells from adipose tissue and bone marrow: induction by growth factors and cartilage-derived matrix. Tissue Eng Part A 16:523-533. 10.1089/ten.TEA.2009.0398

Duan L, Liang Y, Ma B, Zhu W, and Wang D. 2015. Epigenetic regulation in chondrocyte phenotype maintenance for cell-based cartilage repair. Am J Transl Res 7:2127-2140.

Gardner OF, Archer CW, Alini M, and Stoddart MJ. 2013. Chondrogenesis of mesenchymal stem cells for cartilage tissue engineering. Histol Histopathol 28:23-42.

Goepfert C, Lutz V, Lünse S, Kittel S, Wiegandt K, Kammal M, Püschel K, and Pörtner R. 2010. Evaluation of cartilage specific matrix synthesis of human articular chondrocytes after extended propagation on microcarriers by image analysis. The International Journal of Artificial Organs 33:204-218. 
488

489

490

491

492

493

494

495

496

497

498

499

500

501

502

503

504

505

506

507

508

509

510

511

512

513

514

515

516

517

518

519

520

521

522

523

524

525

526

527

528

529

530

531

532

533

534

535

536
Goldring MB, Tsuchimochi K, and Ijiri K. 2006. The control of chondrogenesis. Journal of Cellular Biochemistry 97:33-44. 10.1002/jcb.20652

Gosset M, Berenbaum F, Thirion S, and Jacques C. 2008. Primary culture and phenotyping of murine chondrocytes. Nat Protoc 3:1253-1260. 10.1038/nprot.2008.95

Groeber F, Holeiter M, Hampel M, Hinderer S, and Schenke-Layland K. 2012. Skin tissue engineering-in vivo and in vitro applications. Clin Plast Surg 39:33-58. 10.1016/j.cps.2011.09.007

Grogan SP, Chen X, Sovani S, Taniguchi N, Colwell CW, Jr., Lotz MK, and D'Lima DD. 2014. Influence of cartilage extracellular matrix molecules on cell phenotype and neocartilage formation. Tissue Eng Part A 20:264-274. 10.1089/ten.TEA.2012.0618

Han HS, Lee S, Kim JH, Seong SC, and Lee MC. 2010. Changes in chondrogenic phenotype and gene expression profiles associated with the in vitro expansion of human synovium-derived cells. $J$ Orthop Res 28:1283-1291. 10.1002/jor.21129

Haudenschild DR, McPherson JM, Tubo R, and Binette F. 2001. Differential expression of multiple genes during articular chondrocyte redifferentiation. The Anatomical Record 263:91-98.

Hayman DM, Blumberg TJ, Scott CC, and Athanasiou KA. 2006. The effects of isolation on chondrocyte gene expression. Tissue Eng 12:2573-2581. 10.1089/ten.2006.12.2573

Hettrich CM, Crawford D, and Rodeo SA. 2008. Cartilage repair: third-generation cell-based technologies--basic science, surgical techniques, clinical outcomes. Sports Medicine and Arthroscopy Review 16:230-235. 10.1097/JSA.0b013e31818cdc98

Hidvegi NC, Sales KM, Izadi D, Ong J, Kellam P, Eastwood D, and Butler PE. 2006. A low temperature method of isolating normal human articular chondrocytes. Osteoarthritis Cartilage 14:89-93. 10.1016/j.joca.2005.08.007

Hildner F, Albrecht C, Gabriel C, Redl H, and van Griensven M. 2011. State of the art and future perspectives of articular cartilage regeneration: a focus on adipose-derived stem cells and plateletderived products. Journal of Tissue Engineering and Regenerative Medicine 5:e36-e51. $10.1002 /$ term.386

Hong E, and Reddi AH. 2013. Dedifferentiation and redifferentiation of articular chondrocytes from surface and middle zones: changes in microRNAs-221/-222, -140, and -143/145 expression. Tissue Eng Part A 19:1015-1022. 10.1089/ten.TEA.2012.0055

$\mathrm{Hu}$ DN, Yang PY, Ku MC, Chu CH, Lim AY, and Hwang MH. 2002. Isolation and cultivation of human articular chondrocytes. Kaohsiung J Med Sci 18:113-120.

Jakob M, Démarteau O, Schäfer D, Hintermann B, Dick W, Heberer M, and Martin I. 2001. Specific growth factors during the expansion and redifferentiation of adult human articular chondrocytes enhance chondrogenesis and cartilaginous tissue formation in vitro. Journal of Cellular Biochemistry 81:368-377.

Jonitz, Lochner, Tischer, Hansmann, and Bader. 2012. TGF- $\beta 1$ and IGF-1 influence the re-differentiation capacity of human chondrocytes in $3 \mathrm{D}$ pellet cultures in relation to different oxygen concentrations. Int J Mol Med 30:666-672. 10.3892/ijmm.2012.1042

Kerker JT, Leo AJ, and Sgaglione NA. 2008. Cartilage repair: synthetics and scaffolds: basic science, surgical techniques, and clinical outcomes. Sports Med Arthrosc 16:208-216. 10.1097/JSA.0b013e31818cdbaa

Khan IM, Francis L, Theobald PS, Perni S, Young RD, Prokopovich P, Conlan RS, and Archer CW. 2013. In vitro growth factor-induced bio engineering of mature articular cartilage. Biomaterials 34:1478-1487. 10.1016/j.biomaterials.2012.09.076

Kim TG, Shin H, and Lim DW. 2012. Biomimetic Scaffolds for Tissue Engineering. Advanced Functional Materials 22:2446-2468. 10.1002/adfm.201103083

Kock L, van Donkelaar CC, and Ito K. 2012. Tissue engineering of functional articular cartilage: the current status. Cell Tissue Res 347:613-627. 10.1007/s00441-011-1243-1

Lackie JM. 2013. The dictionary of cell and molecular biology. Amsterdam: Academic Press/Elsevier. 
537

538

539

540

541

542

543

544

545

546

547

548

549

550

551

552

553

554

555

556

557

558

559

560

561

562

563

564

565

566

567

568

569

570

571

572

573

574

575

576

577

578

579

580

581

582

583

584

585

Lagana M, Arrigoni C, Lopa S, Sansone V, Zagra L, Moretti M, and Raimondi MT. 2014. Characterization of articular chondrocytes isolated from 211 osteoarthritic patients. Cell Tissue Bank 15:59-66. 10.1007/s10561-013-9371-3

Lee SY, Wee AS, Lim CK, Abbas AA, Selvaratnam L, Merican AM, Ahmad TS, and Kamarul T. 2013. Supermacroporous poly(vinyl alcohol)-carboxylmethyl chitosan-poly(ethylene glycol) scaffold: an in vitro and in vivo pre-assessments for cartilage tissue engineering. J Mater Sci Mater Med 24:1561-1570. 10.1007/s10856-013-4907-4

Li C, Wang L, Yang Z, Kim G, Chen H, and Ge Z. 2012. A viscoelastic chitosan-modified threedimensional porous poly(L-lactide-co-epsilon-caprolactone) scaffold for cartilage tissue engineering. J Biomater Sci Polym Ed 23:405-424. 10.1163/092050610X551970

Li L, Ma Y, Li X, Li X, Bai C, Ji M, Zhang S, Guan W, and Li J. 2015. Isolation, Culture, and Characterization of Chicken Cartilage Stem/Progenitor Cells. Biomed Res Int 2015:586290. $10.1155 / 2015 / 586290$

Louveau I, Chaudhuri S, and Etherton TD. 1991. An improved method for isolating RNA from porcine adipose tissue. Anal Biochem 196:308-310.

Makris EA, Gomoll AH, Malizos KN, Hu JC, and Athanasiou KA. 2015. Repair and tissue engineering techniques for articular cartilage. Nat Rev Rheumatol 11:21-34. 10.1038/nrrheum.2014.157

Maver T, Maver U, Kleinschek SK, Raščan MI, and Smrke MD. 2015. Advanced therapies of skin injuries. Wiener klinische Wochenschrift 127:187-198. 10.1007/s00508-015-0859-7

McNickle AG, Provencher MT, and Cole BJ. 2008. Overview of existing cartilage repair technology. Sports Medicine and Arthroscopy Review 16:196-201. 10.1097/JSA.0b013e31818cdb82

Mirando AJ, Dong Y, Kim J, and Hilton MJ. 2014. Isolation and culture of murine primary chondrocytes. Methods Mol Biol 1130:267-277. 10.1007/978-1-62703-989-5_20

Mohd Hilmi AB, and Halim AS. 2015. Vital roles of stem cells and biomaterials in skin tissue engineering. World J Stem Cells 7:428-436. 10.4252/wjsc.v7.i2.428

Naranda J, Susec M, Maver U, Gradisnik L, Gorenjak M, Vukasovic A, Ivkovic A, Rupnik MS, Vogrin M, and Krajnc P. 2016. Polyester type polyHIPE scaffolds with an interconnected porous structure for cartilage regeneration. Sci Rep 6:28695. 10.1038/srep28695

Niemeyer P, Albrecht D, Andereya S, Angele P, Ateschrang A, Aurich M, Baumann M, Bosch U, Erggelet C, Fickert S, Gebhard H, Gelse K, Günther D, Hoburg A, Kasten P, Kolombe T, Madry H, Marlovits S, Meenen NM, Müller PE, Nöth U, Petersen JP, Pietschmann M, Richter W, Rolauffs B, Rhunau K, Schewe B, Steinert A, Steinwachs MR, Welsch GH, Zinser W, and Fritz J. 2016. Autologous chondrocyte implantation (ACI) for cartilage defects of the knee: A guideline by the working group "Clinical Tissue Regeneration" of the German Society of Orthopaedics and Trauma (DGOU). Knee. 10.1016/j.knee.2016.02.001

Oseni AO, Butler PE, and Seifalian AM. 2013. Optimization of chondrocyte isolation and characterization for large-scale cartilage tissue engineering. Journal of Surgical Research 181:4148. http://dx.doi.org/10.1016/j.jss.2012.05.087

Otero M, Favero M, Dragomir C, El Hachem K, Hashimoto K, Plumb DA, and Goldring MB. 2005. Human Chondrocyte Cultures as Models of Cartilage-Specific Gene Regulation. Methods in molecular medicine 107:69-95.

Otero M, Favero M, Dragomir C, Hachem KE, Hashimoto K, Plumb DA, and Goldring MB. 2012. Human Chondrocyte Cultures as Models of Cartilage-Specific Gene Regulation. In: Mitry RR, and Hughes RD, eds. Human Cell Culture Protocols. Totowa, NJ: Humana Press, 301-336.

Pei M, and He F. 2012. Extracellular matrix deposited by synovium-derived stem cells delays replicative senescent chondrocyte dedifferentiation and enhances redifferentiation. J Cell Physiol 227:21632174. 10.1002/jcp.22950

Peterson BE, Jiwanlal A, Della Rocca GJ, and Crist BD. 2015. Orthopedic Trauma and Aging: It Isn't Just About Mortality. Geriatr Orthop Surg Rehabil 6:33-36. 10.1177/2151458514565663 
586

587

588

589

590

591

592

593

594

595

596

597

598

599

600

601

602

603

604

605

606

607

608

609

610

611

612

613

614

615

616

617

618

619

620

621

622

623

624

625

626

627

628

629

630

631

632

633

634

635

Richter DL, Schenck RC, Wascher DC, and Treme G. 2016. Knee Articular Cartilage Repair and Restoration Techniques: A Review of the Literature. Sports Health 8:153-160. $10.1177 / 1941738115611350$

Robb CA, El-Sayed C, Matharu GS, Baloch K, and Pynsent P. 2012. Survival of autologous osteochondral grafts in the knee and factors influencing outcome. Acta Orthop Belg 78:643-651.

Rodriguez-Vazquez M, Vega-Ruiz B, Ramos-Zuniga R, Saldana-Koppel DA, and Quinones-Olvera LF. 2015. Chitosan and Its Potential Use as a Scaffold for Tissue Engineering in Regenerative Medicine. Biomed Res Int 2015:821279. 10.1155/2015/821279

Rosenzweig DH, Solar-Cafaggi S, and Quinn TM. 2012. Functionalization of dynamic culture surfaces with a cartilage extracellular matrix extract enhances chondrocyte phenotype against dedifferentiation. Acta Biomaterialia 8:3333-3341. 10.1016/j.actbio.2012.05.032

Schnabel M, Marlovits S, Eckhoff G, Fichtel I, Gotzen L, Vecsei V, and Schlegel J. 2002a. Dedifferentiation-associated changes in morphology and gene expression in primary human articular chondrocytes in cell culture. Osteoarthritis Cartilage 10:62-70. 10.1053/joca.2001.0482

Schnabel M, Marlovits S, Eckhoff G, Fichtel I, Gotzen L, Vécsei V, and Schlegel J. 2002b. Dedifferentiation-associated changes in morphology and gene expression in primary human articular chondrocytes in cell culture. Osteoarthritis and Cartilage 10:62-70. 10.1053/joca.2001.0482

Schneevoigt J, Fabian C, Leovsky C, Seeger J, and Bahramsoltani M. 2016. In Vitro Expression of the Extracellular Matrix Components Aggrecan, Collagen Types I and II by Articular CartilageDerived Chondrocytes. Anatomia, Histologia, Embryologia. 10.1111/ahe.12230

Schrobback K, Klein TJ, Schuetz M, Upton Z, Leavesley DI, and Malda J. 2011. Adult human articular chondrocytes in a microcarrier-based culture system: expansion and redifferentiation. Journal of Orthopaedic Research: Official Publication of the Orthopaedic Research Society 29:539-546. $10.1002 /$ jor.21264

Seda Tigli R, Ghosh S, Laha MM, Shevde NK, Daheron L, Gimble J, Gumusderelioglu M, and Kaplan DL. 2009. Comparative chondrogenesis of human cell sources in 3D scaffolds. J Tissue Eng Regen Med 3:348-360. 10.1002/term.169

Shi S, Chan AG, Mercer S, Eckert GJ, and Trippel SB. 2014. Endogenous versus exogenous growth factor regulation of articular chondrocytes. J Orthop Res 32:54-60. 10.1002/jor.22444

Shortkroff S, and Spector M. 1999. Isolation and in vitro proliferation of chondrocytes, tenocytes, and ligament cells. Methods Mol Med 18:195-203. 10.1385/0-89603-516-6:195

Stellavato A, Tirino V, de Novellis F, Della Vecchia A, Cinquegrani F, De Rosa M, Papaccio G, and Schiraldi C. 2016. Biotechnological Chondroitin a Novel Glycosamminoglycan With Remarkable Biological Function on Human Primary Chondrocytes. J Cell Biochem 117:2158-2169. $10.1002 / \mathrm{jcb} .25556$

Strzelczyk P, Benke G, and Gorecki A. 2001. Methods for the isolation and culture of human articular chondrocytes. Ortop Traumatol Rehabil 3:213-215.

Su K, Lau TT, Leong W, Gong Y, and Wang D-A. 2012. Creating a Living Hyaline Cartilage Graft Free from Non-Cartilaginous Constituents: An Intermediate Role of a Biomaterial Scaffold. Advanced Functional Materials 22:972-978. 10.1002/adfm.201102884

Thierry-Mieg D, and Thierry-Mieg J. 2006. AceView: a comprehensive cDNA-supported gene and transcripts annotation. Genome Biol 7 Suppl 1:S12 11-14. 10.1186/gb-2006-7-s1-s12

Thirion S, and Berenbaum F. 2004. Culture and phenotyping of chondrocytes in primary culture. Methods Mol Med 100:1-14. 10.1385/1-59259-810-2:001

Tuli R, Li W-J, and Tuan RS. 2003. Current state of cartilage tissue engineering. Arthritis Res Ther 5:235-238.

Univerzitetni klinicni center M. 2014. Letno porocilo 2013. Maribor: Univerzitetni klinicni center.

Wu L, Gonzalez S, Shah S, Kyupelyan L, Petrigliano FA, McAllister DR, Adams JS, Karperien M, Tuan TL, Benya PD, and Evseenko D. 2014. Extracellular matrix domain formation as an indicator of 
636 chondrocyte dedifferentiation and hypertrophy. Tissue Eng Part C Methods 20:160-168.

$637 \quad 10.1089 /$ ten.TEC.2013.0056

$638 \mathrm{Xu} \mathrm{J}$, and Zhang C. 2014. In vitro isolation and cultivation of human chondrocytes for osteoarthritis renovation. In Vitro Cell Dev Biol Anim 50:623-629. 10.1007/s11626-014-9742-5

640 